\title{
Effects of Sb Content on Solidification Pathways and Grain Size of AZ91 Magnesium Alloy
}

\author{
Dan-Hui Hou $\cdot$ Song-Mao Liang $\cdot$ Rong-Shi Chen $\cdot$ Chuang Dong $\cdot$ En-Hou Han
}

Received: 13 April 2014/Revised: 6 May 2014/Published online: 26 November 2014

(C) The Chinese Society for Metals and Springer-Verlag Berlin Heidelberg 2014

\begin{abstract}
The phase constitution and solidification pathways of AZ91 $+x \operatorname{Sb}(x=0,0.1,0.5,1$, in wt $\%)$ alloys were investigated through ways of microstructure observation, thermal analysis technique, and thermodynamic calculation. It was found that the non-equilibrium solidification microstructure of AZ91 $+x \mathrm{Sb}(x=0.1,0.5,1)$ is composed of $\alpha-\mathrm{Mg}$ matrix, $\beta-\mathrm{Mg}_{17} \mathrm{Al}_{12}$ phase, and intermetallic compound $\mathrm{Mg}_{3} \mathrm{Sb}_{2}$. The grain size of the alloys with different $\mathrm{Sb}$ contents was quantitatively determined by electron backscattered diffraction technique which shows no grain refinement in Sb-containing AZ91 alloy. Thermodynamic calculations are in reasonable agreement with thermal analysis results, showing that the $\mathrm{Mg}_{3} \mathrm{Sb}_{2}$ phase forms after $\alpha-\mathrm{Mg}$ nucleation, thus impossible acts as heterogeneous nucleus for $\alpha-\mathrm{Mg}$ dendrite. Besides, the solid fraction at dendrite coherency point $\left(f_{\mathrm{s}}^{\mathrm{DCP}}\right)$ determined from thermal analysis decreases slightly with increasing $\mathrm{Sb}$ content, which is consistent with the fact that $\mathrm{Sb}$ does not refine the grain size of AZ91 alloy.
\end{abstract}

KEY WORDS: Mg-Al-Zn-Sb alloy; Solidification pathways; Nucleation; Grain size; Dendrite coherency

\section{Introduction}

Magnesium alloys are seeing rapid growth in the applications of aerospace, aviation, and automobile industry due to their weight-saving advantages [1,2]. The AZ91 alloy, with a good combination of high strength at ambient temperature, good corrosion resistance, and castability, is the most widely used magnesium alloy in automobile industry [3, 4].

Available online at http://link.springer.com/journal/40195

D.-H. Hou · C. Dong

School of Material Science and Engineering, Dalian University of Technology, Dalian 116024, China

D.-H. Hou · R.-S. Chen $(\bowtie) \cdot$ E.-H. Han Institute of Metal Research, Chinese Academy of Science, Shenyang 110016, China

e-mail: rschen@imr.ac.cn

S.-M. Liang

Institute of Metallurgy, Clausthal University of Technology, 38678 Clausthal-Zellerfeld, Germany
However, the $\gamma-\mathrm{Mg}_{17} \mathrm{Al}_{12}$ phase which is the main strengthen phase in AZ91 alloy softens and weaken at temperature higher than $130{ }^{\circ} \mathrm{C}$, thus the application of AZ91 alloy at elevated temperature environment such as power transmission components and engine block is still limited $[5,6]$. Many attempts have been exerted through introducing $\mathrm{Bi}, \mathrm{Ca}, \mathrm{RE}, \mathrm{Sr}$, and $\mathrm{Sb}$ by forming some thermal stable intermetallic phases in order to improve the elevated temperature mechanical properties of AZ91 alloy [7-15].

Antimony ( $\mathrm{Sb}$ ) is one of the popular alloying elements for modification of AZ91 alloy, as the formed $\mathrm{Mg}_{3} \mathrm{Sb}_{2}$ phase shows much better thermal stability than $\gamma-\mathrm{Mg}_{17} \mathrm{Al}_{12}$ phase $[12,16]$. The introduction of $\mathrm{Sb}$ can increase the creep resistance of AZ91 alloy $[12,16]$ as well as some other $\mathrm{Mg}$ alloys [16-18]. Besides some researchers also reported that the introduction of $\mathrm{Sb}$ could obviously refine the grain size of $\alpha-\mathrm{Mg}$ phase $[12,19]$ and the $\mathrm{Mg}_{3} \mathrm{Sb}_{2}$ phase was the heterogeneous nucleus of $\alpha-\mathrm{Mg}$ phase [10]. However, no convincing microstructure proofs have been provided and the differential thermal analysis (DTA) result might have been wrongly interpreted [10]. Therefore, it is necessary to 
investigate systematically the effect of Sb on solidification behavior and microstructure evolution of AZ91 alloy.

Recent developments in the use of electron backscattered diffraction (EBSD) have made it an excellent tool for quantitative metallographic observation compared to conventional optical microscopy, since a number of important microstructural information, in particular, the parameters relating to the grain orientations and size are now available from EBSD observation [20, 21]. The AZ91 + Sb alloys are often dendrite with interdendritic intermetallic phases and hardly reveal the grain boundaries through ordinary etch and optical microscopy observation, the EBSD is the best option for quantitatively determining the grain size of the alloys.

The grain size of alloys related closely with their solidification characteristics under equilibrium and nonequilibrium conditions [22,23]. And the prominent method for determination of solidification characteristics includes thermal analysis and thermodynamic calculations, etc. The solidification characteristics, e.g., dendrite nucleation and dendrite coherency, can be derived from thermal analysis of the alloy solidification [23]. The dendrite coherency point (DCP) refers to what the continuously growing dendrites began to impact their neighbors. In accordance with this understanding, the grain size in solidifying microstructure has actually been decided and will not change at/after this point. Correspondingly, the solid fraction $\left(f_{\mathrm{s}}\right)$ at DCP has been defined as $f_{\mathrm{s}}^{\mathrm{DCP}}$, and a higher $f_{\mathrm{s}}^{\mathrm{DCP}}$ means finer grain size after solidification of alloy [24-26].

Thermodynamic calculations are effective complements to traditional experimental ways for obtaining some details not perceptible from thermal analysis experiments, such as formation of micro phases during alloy solidification. In recent years, the thermodynamic descriptions of $\mathrm{Mg}-\mathrm{Al}-\mathrm{Zn}$, and $\mathrm{Mg}-$ $\mathrm{Al}-\mathrm{Sb}$ and $\mathrm{Mg}-\mathrm{Al}-\mathrm{Zn}-\mathrm{Sb}$ systems have been optimized by researchers [27-29], which benefited a lot to the consideration of Sb effects on solidification characteristics of AZ91 alloy.

In the present research, the effects of $\mathrm{Sb}$ addition on solidification pathways and grain size of $\mathrm{AZ} 91+x \mathrm{Sb}$ $(x=0,0.1,0.5,1$, in wt $\%)$ alloys were studied particularly by SEM, EBSD observation, and thermal analysis. And the effects of $\mathrm{Sb}$ on nucleation of $\alpha-\mathrm{Mg}$ dendrites were discussed based on thermodynamic calculations of $\mathrm{Mg}-\mathrm{Al}-$ $\mathrm{Zn}-\mathrm{Sb}$ phase diagram. After the analysis, some new insight into the effects of $\mathrm{Sb}$ on solidification pathways and grain size of AZ91 alloys will be presented.

\section{Experimental}

\subsection{Alloy Preparation}

The alloys were smelted in a $12.5 \mathrm{~kg}$ crucible by electric resistance furnace. The raw materials used for the
Table 1 Chemical compositions of the investigated alloys (wt $\%$ )

\begin{tabular}{lllll}
\hline Alloys & $\mathrm{Al}$ & $\mathrm{Zn}$ & $\mathrm{Mn}$ & $\mathrm{Sb}$ \\
\hline $\mathrm{AZ91}$ & 8.78 & 0.69 & 0.30 & - \\
$\mathrm{AZ91}+0.1 \mathrm{Sb}$ & 8.84 & 0.65 & 0.32 & 0.09 \\
$\mathrm{AZ91}+0.5 \mathrm{Sb}$ & 9.18 & 0.92 & 0.24 & 0.42 \\
$\mathrm{AZ91}+1.0 \mathrm{Sb}$ & 8.66 & 0.90 & 0.26 & 1.02 \\
\hline
\end{tabular}

preparation of the studied alloys were commercial pure $\mathrm{Mg}$ (99.9\%), $\mathrm{Al}$ (99.9\%), Zn (99.9\%), Sb (99.5\%), and $\mathrm{Al}-10.0$ wt $\% \mathrm{Mn}$ master alloy. Firstly, the pure magnesium was melted in the crucible, and then the preheated $\mathrm{Al}-\mathrm{Mn}$ master alloy, $\mathrm{Al}, \mathrm{Zn}$, and $\mathrm{Sb}$ were added into the melt at about $730{ }^{\circ} \mathrm{C}$. Then the melt was held at $720{ }^{\circ} \mathrm{C}$ for $5 \mathrm{~min}$. The refining was carried out at $720{ }^{\circ} \mathrm{C}$ for about $10 \mathrm{~min}$ and the alloy melt was modified with $0.4 \mathrm{wt} \% \mathrm{MgCO}_{3}$ at about $730{ }^{\circ} \mathrm{C}$. Finally, the melt was heated to $780{ }^{\circ} \mathrm{C}$ and held for about $15 \mathrm{~min}$. And the melt was poured at $710^{\circ} \mathrm{C}$ into metal molds which preheated to about $200{ }^{\circ} \mathrm{C}$ to cast the alloy ingots. The analyzed chemical compositions of the alloys are listed in Table 1. The samples for microstructure observation, EBSD observation, and thermal analysis were cut from the ingots.

\subsection{Microstructure Observation}

Microstructure observation of the investigated alloys was carried out on a PhilipsXL30 ESEM-FEG/EDAX scanning electron microscope (SEM). The grain size of the alloys was analyzed by the standard linear intercept method on images acquired by EBSD. The specimens for EBSD observation were polished with $5000 \# \mathrm{SiC}$ abrasive, and then treated by electrolytic polishing with solution of $10 \%$ perchloric acid and 90\% alcohol. Samples for metallographic observation and grain size determination were cut from same location of the casting ingots. X-ray diffraction analysis was carried out to confirm the phase constitution of the alloys using D/Max-2500PC X-ray diffraction (XRD).

\subsection{Thermal Analysis}

Samples for thermal analysis cut from the cast ingots were machined into cylinders of $30 \mathrm{~mm}$ in diameter and $60 \mathrm{~mm}$ in length. Thermal analyses were performed based on the two-thermocouple method that was developed by Liang et al. [24]. The samples were remelted in a steel crucible in an electrical resistance furnace, then two K-type thermocouples $(\varnothing=0.3 \mathrm{~mm})$ were immersed into the melt, of which one was placed at the center of the crucible $\left(T_{\mathrm{c}}\right)$ and the other close to the inner wall $\left(T_{\mathrm{w}}\right)$ at exactly the same depth in the melt (30 $\mathrm{mm}$ from the bottom). Then the melt 
in graphite crucible was heated to $720^{\circ} \mathrm{C}$ and held for $10 \mathrm{~min}$ before solidified in the air at about $1{ }^{\circ} \mathrm{C} / \mathrm{s}$. During the melt solidification, its temperature changes were continuously recorded using a high-speed data acquisition system linked to the computer. Each set of measurement was carried out at least twice to ensure the reproducibility of the experiment result. The cooling curves and their first derivative curves were plotted by Origin 8.5 data analysis software. In order to calculate the solid fraction at DCP of the alloys, a zero curve was calculated based on the Newtonian model adopted by Thompson et al. [30]. And the solid fraction is determined by calculating the area between the baseline and first derivative curve with the following equation:

$f_{\mathrm{s}}=\frac{\int_{0}^{t}\left[\left(\frac{\mathrm{d} T}{\mathrm{~d} t}\right)_{\mathrm{cc}}-\left(\frac{\mathrm{d} T}{\mathrm{~d} t}\right)_{\mathrm{zc}}\right] \mathrm{d} t}{\int_{0}^{t \mathrm{~s}}\left[\left(\frac{\mathrm{d} T}{\mathrm{~d} t}\right)_{\mathrm{cc}}-\left(\frac{\mathrm{d} T}{\mathrm{~d} t}\right)_{\mathrm{zc}}\right] \mathrm{d} t}$,

where $\mathrm{cc}$ and $\mathrm{zc}$ represent the cooling curve and baseline. The dendrite coherency temperature of the alloys $\left(T_{\mathrm{DCP}}\right)$ was determined by the first maximum temperature difference between the center $\left(T_{\mathrm{c}}\right)$ and the wall thermocouples $\left(T_{\mathrm{w}}\right)$ during the $\alpha-\mathrm{Mg}$ formation, as shown in Fig. 1. And the solid fraction at $T_{\mathrm{DCP}}$ is $f_{\mathrm{s}}^{\mathrm{DCP}}$.

\subsection{Thermodynamic Calculation}

In order to predict the solidification behavior of the experimental alloys, a thermodynamic dataset with five element $\mathrm{Mg}-\mathrm{Al}-\mathrm{Zn}-\mathrm{Mn}-\mathrm{Sb}$ system has been developed by combining the $\mathrm{Mg}-\mathrm{Al}-\mathrm{Mn}-\mathrm{Zn}$ [31] quaternary system and $\mathrm{Mg}-\mathrm{Al}-\mathrm{Sb}$ [27] ternary system. Although some problems exist in the liquid phase description which was reported in Ref. [27] as pointed out by Ref. [28], the Gibbs energy description of $\mathrm{Mg}_{3} \mathrm{Sb}_{2}$ phase is good enough and the calculated results show reasonable agreement with experimental results at $\mathrm{Mg}-\mathrm{Al}$ rich side. In the later published thermodynamic description of $\mathrm{Mg}-\mathrm{Al}-\mathrm{Sb}$ system [28], the liquid phase was modeled as quasi-chemical model which can only be used in FactSage. All thermodynamic calculations in the present work were performed using the integrated software package Pandat [32].

\section{Results and Discussion}

\subsection{Microstructure of AZ91 + xSb Alloys}

The solidification microstructure of AZ91 $+x$ Sb alloys is presented in Fig. 2. As can be seen in Fig. 2a, the microstructure of AZ91 alloy is composed of $\alpha-\mathrm{Mg}$ dendrites and

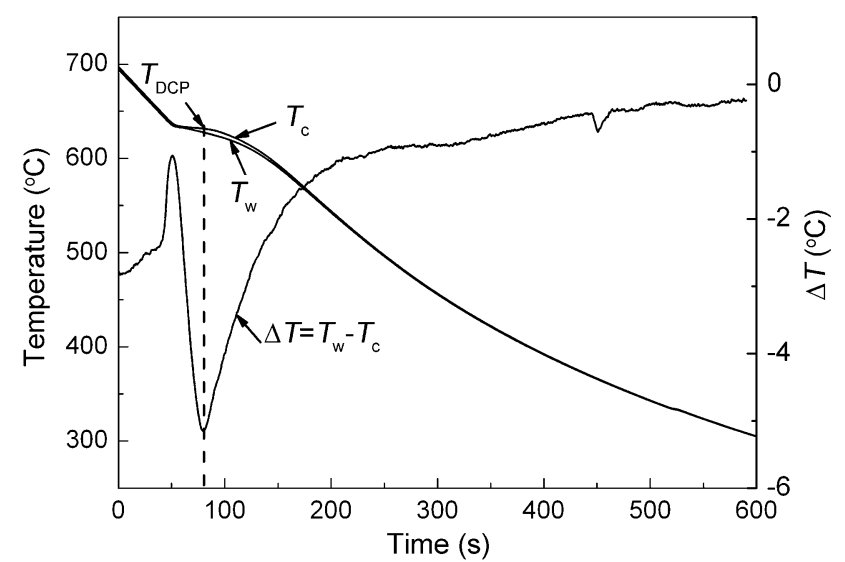

Fig. 1 Determination of dendrite coherency point through thermal analysis result

net- or block-shaped $\gamma-\mathrm{Mg}_{17} \mathrm{Al}_{12}$ phase. When $0.1 \mathrm{wt} \% \mathrm{Sb}$ is added into the alloy, the net-shaped $\gamma-\mathrm{Mg}_{17} \mathrm{Al}_{12}$ phase is not markedly refined and some white particles are seen inside the $\gamma$ phases, as shown in Fig. $2 b$. These white particles are identified as $\mathrm{Mg}_{3} \mathrm{Sb}_{2}$ phase by EDX. As $\mathrm{Sb}$ content increases, the $\mathrm{Mg}_{3} \mathrm{Sb}_{2}$ phase becomes needleshaped phases as shown in Fig. 2c, and then changes to block shaped as seen in Fig. 2d. It is also observed that $\mathrm{Sb}$ addition into AZ91 does not appreciably change the quantity of the $\gamma-\mathrm{Mg}_{17} \mathrm{Al}_{12}$ phase. This is due to that no $\mathrm{Al}-$ $\mathrm{Sb}$ compounds are formed after $\mathrm{Sb}$ addition, so $\mathrm{Al}$ still forms $\mathrm{Mg}_{17} \mathrm{Al}_{12}$ with $\mathrm{Mg}$ after $\mathrm{Sb}$ addition [20].

Figure 3 presents the X-ray diffraction patterns of AZ91 $+x$ Sb alloys. In Fig. 3, the peaks representing $\alpha-\mathrm{Mg}$ phase and $\gamma-\mathrm{Mg}_{17} \mathrm{Al}_{12}$ phase are detected on the XRD pattern of AZ91 alloy. And the peaks representing $\mathrm{Mg}_{3} \mathrm{Sb}_{2}$ phase are found when $\mathrm{Sb}$ is added in AZ91 alloy, which is consistent with microstructure observation. In one word, no significant change in the solidification microstructure of AZ91 alloy occurs after $\mathrm{Sb}$ addition, except that some micro-phase of $\mathrm{Mg}_{3} \mathrm{Sb}_{2}$ forms inside the $\gamma-\mathrm{Mg}_{17} \mathrm{Al}_{12}$ phase. Since the $\mathrm{Mg}_{3} \mathrm{Sb}_{2}$ phase distributes mainly on grain boundaries or dendrite arm spaces, it appears unlikely for these $\mathrm{Mg}_{3} \mathrm{Sb}_{2}$ particles to act as the heterogeneous nucleus for $\alpha-\mathrm{Mg}$ dendrites.

\subsection{Effects of $\mathrm{Sb}$ on the Grain Size}

The EBSD images of the AZ91 $+x \mathrm{Sb}$ alloys are shown in Fig. 4, in which the grain boundaries in the solidification microstructure are seen clearly. By the standard linear intercept method, the average grain size (AGS) of the four alloys is determined to be $217,231,251$, and $246 \mu \mathrm{m}$, respectively. The result shows that $\mathrm{Sb}$ addition has no grain refinement effect on AZ91 alloy, which is contradicted 

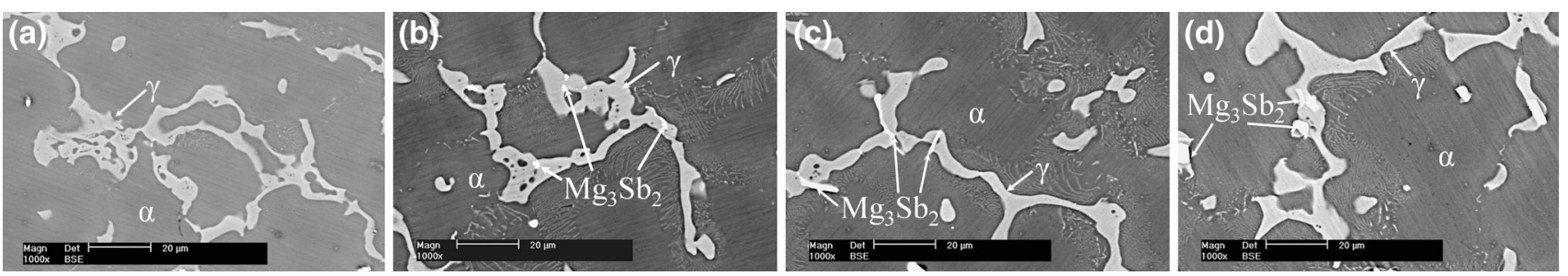

Fig. 2 SEM images showing the microstructures of AZ91 $+x \mathrm{Sb}$ alloys: a AZ91 alloy; b AZ91 + 0.1Sb alloy; c AZ91 + 0.5Sb alloy; d AZ91 + 1.0Sb alloy

with previous works [12,20]. Yuan et al. [12] only claimed that $\mathrm{Sb}$ addition refined the grain size of AZ91 alloy without providing any microstructure comparison, while Wang et al. [19] presented the OM images with grain boundaries hardly seen. On the other hand, Srinivasan et al. [16] reported that the grain size of AZ91 is $(80 \pm 10) \mu \mathrm{m}$ and AZ91 $+0.5 \mathrm{Sb}$ is $(70 \pm 15) \mu \mathrm{m}$ in their results, which indicate that the refinement effect is not obvious either. Little grain refinement effect has also been observed in the Sb-added ZA84 alloys [17].

\subsection{Solidification Pathways of AZ91 + xSb Alloys}

The solidification pathways of AZ91 $+x \mathrm{Sb}$ alloys were investigated by both thermal analysis and thermodynamic calculations. Figure 5 shows the thermal analysis results of the investigated alloys, including cooling curves, the first derivative curves, and the base line. As shown in Fig. 5, two obvious peaks are detected from the first derivative curves of all the investigated alloys. The two peaks are marked as peak A and peak B, respectively. Peak A represents the formation of $\alpha-\mathrm{Mg}$ phase and Peak B represents the formation of $\gamma-\mathrm{Mg}_{17} \mathrm{Al}_{12}$ phase. No other obvious peaks are detected from the first derivative curves of AZ91 + 0.1Sb alloy, but a small peak appears at about $513.9^{\circ} \mathrm{C}$ on the curve of AZ91 + 0.5Sb alloy, and become more significant at about $542.8^{\circ} \mathrm{C}$ on the curve of AZ91 + 1 Sb alloy, which are marked as peak $\mathrm{C}$ in Fig. 5 . The characteristic temperatures derived from thermal analysis results are listed in Table 2.

Figure 6 shows the calculated derivatives of total enthalpy $(\mathrm{d} H / \mathrm{d} T)$ versus temperature curve of AZ91 under Scheil solidification simulation condition compared with $\mathrm{AZ} 91+1 \mathrm{Sb}$ alloy. A tiny peak at $546{ }^{\circ} \mathrm{C}$ refers to the formation of $\mathrm{Mg}_{3} \mathrm{Sb}_{2}$ phase on the curve of $\mathrm{AZ} 91+1.0 \mathrm{Sb}$ alloy, which indicates that the small peak $\mathrm{C}$ in the first derivative curves of $\mathrm{AZ} 91+0.5 \mathrm{Sb}$ and $\mathrm{AZ} 91+1 \mathrm{Sb}$ alloys should also correspond to the formation of $\mathrm{Mg}_{3} \mathrm{Sb}_{2}$ phase. The calculated phase transition temperature of these three main phases under Scheil simulation of all the four experimental alloys are collected in Table 3. The calculated results show reasonable agreement with the

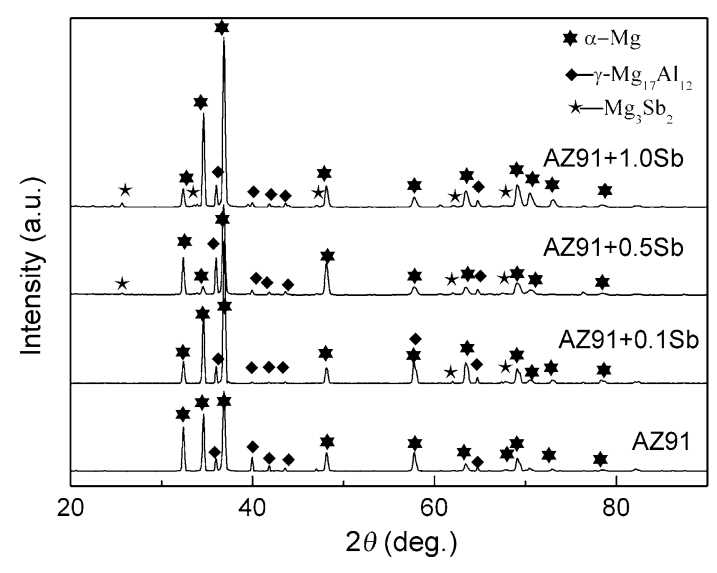

Fig. 3 XRD patterns of AZ91 $+x$ Sb alloys

experimental determined values with considering the possible composition variation of the samples and temperature error bar.

Figure 7 shows the calculated equilibrium vertical section of $\mathrm{Mg}-9 \mathrm{Al}-1 \mathrm{Zn}-x \mathrm{Sb}$ system compared with the thermal signal of the experimental alloys. Under equilibrium condition, liquid phase disappears at temperature below about $450{ }^{\circ} \mathrm{C}$, with $\alpha-\mathrm{Mg}$ and $\mathrm{Mg}_{3} \mathrm{Sb}_{2}$ two phase regions from 450 to $383{ }^{\circ} \mathrm{C}$, which means the $\gamma-\mathrm{Mg}_{17} \mathrm{Al}_{12}$ phase in the as-cast structure formed during non-equilibrium solidification can be dissolved into $\alpha-\mathrm{Mg}$ through solution heat treatment within this temperature window. The $\gamma-\mathrm{Mg}_{17} \mathrm{Al}_{12}$ phase appearing in the three phase region at temperature lower than $380{ }^{\circ} \mathrm{C}$ indicates that $\gamma-\mathrm{Mg}_{17} \mathrm{Al}_{12}$ phase could precipitate again through the aging treatment. The calculated result is supported by heat treatment experimental results [12] and can provide some guides for the heat treatment condition optimization.

\subsection{On the Assumption of Nucleation of $\alpha-\mathrm{Mg}$ Phase on $\mathrm{Mg}_{3} \mathrm{Sb}_{2}$ Phase}

The assumption that $\mathrm{Mg}_{3} \mathrm{Sb}_{2}$ phase could be effective nucleation sites for $\alpha-\mathrm{Mg}$ phase was proposed by Balasubramani et al. [10], who also measured the DTA heating 

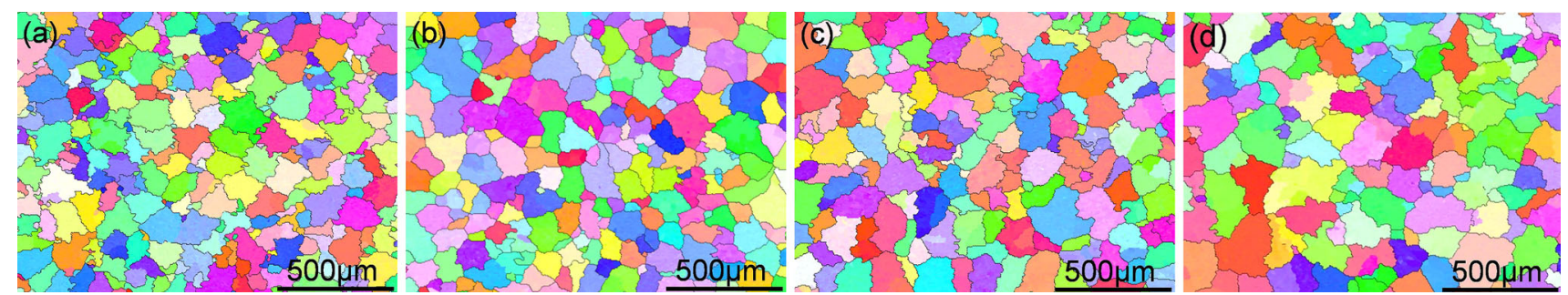

Fig. 4 EBSD images of AZ91 + $x$ Sb alloys: a AZ91 alloy, average grain size is $217 \mu \mathrm{m}$; b AZ91 + 0.1Sb alloy, average grain size is $231 \mu \mathrm{m}$,; c AZ91 + 0.5Sb alloy, average grain size is $251 \mu \mathrm{m}$; d AZ91 + 1.0Sb alloy, average grain size is $246 \mu \mathrm{m}$

(a)

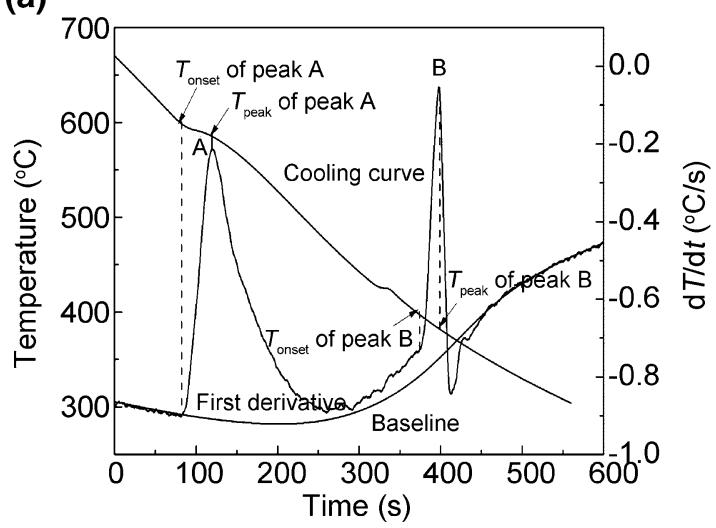

(c)

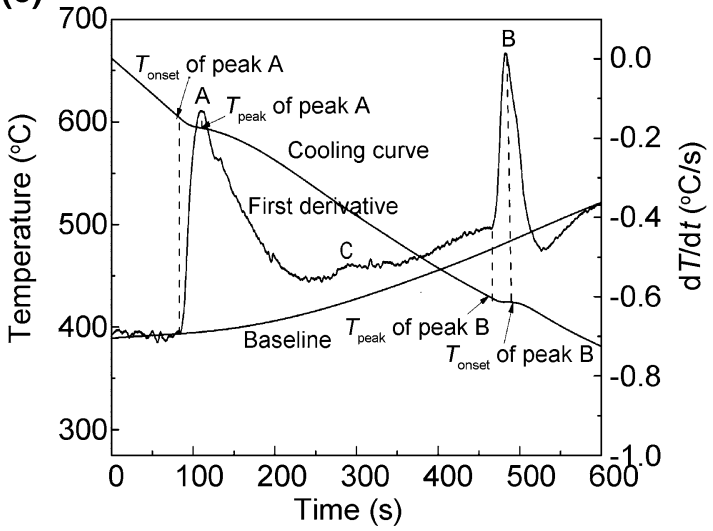

(b)

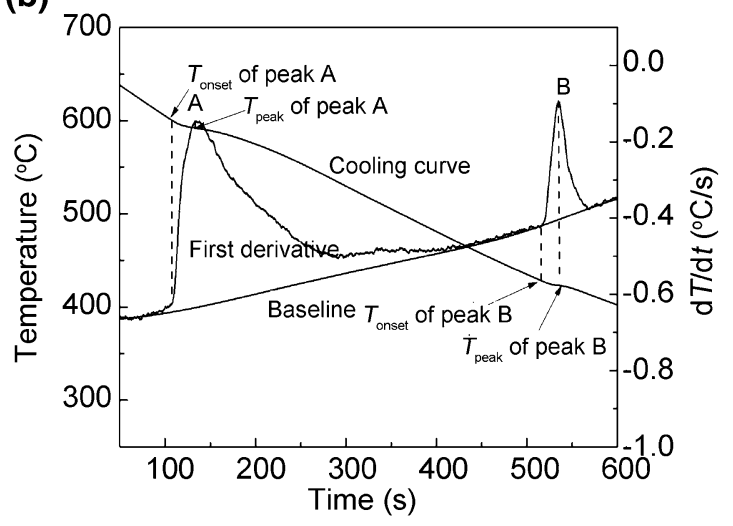

(d)



Fig. 5 Thermal analysis results of AZ91 alloys: a AZ91 alloy; b AZ91 + 0.1Sb alloy; c AZ91 + 0.5Sb alloy; d AZ91 + 1.0Sb alloy

curve of AZ91 + 0.5Sb alloy, on which an obvious turning point was observed at temperature higher than the melting of $\alpha-\mathrm{Mg}$ phase. They explained this point as the $\mathrm{Mg}_{3} \mathrm{Sb}_{2}$ phase dissolution. Then they draw a conclusion that the $\mathrm{Mg}_{3} \mathrm{Sb}_{2}$ phase would precipitate before $\alpha-\mathrm{Mg}$ phase and might be the effective nuclei [10]. However, after carefully examined their experimental detail description and their DTA spectrum, we believe this interpretation is unacceptable for three reasons. First, only $0.47 \mathrm{wt} \% \mathrm{Sb}$ was contained in their AZ91 + 0.5Sb alloy, so a small amount of the $\mathrm{Mg}_{3} \mathrm{Sb}_{2}$ phase could not generate such a strong thermal event on the DTA heating curve shown in Ref. [10], even though it occurs at temperature higher than the $\alpha$-Mg phase
Table 2 Characteristic temperatures obtained from the cooling curves of the central thermocouple

\begin{tabular}{llllll}
\hline Alloys & \multicolumn{2}{l}{ Peak A } & & \multicolumn{2}{l}{ Peak B } \\
\cline { 2 - 3 } \cline { 6 - 6 } \cline { 5 - 6 } & $T_{\text {onset }}\left({ }^{\circ} \mathrm{C}\right)$ & $T_{\text {peak }}\left({ }^{\circ} \mathrm{C}\right)$ & & $T_{\text {onset }}\left({ }^{\circ} \mathrm{C}\right)$ & $T_{\text {peak }}\left({ }^{\circ} \mathrm{C}\right)$ \\
\hline AZ91 & 610 & 592 & & 435 & 425 \\
$\mathrm{AZ91+0.1Sb}$ & 607 & 592 & & 429 & 423 \\
$\mathrm{AZ91+0.5Sb}$ & 603 & 594 & & 428 & 424 \\
$\mathrm{AZ91+1.0Sb}$ & 602 & 594 & & 426 & 423 \\
\hline
\end{tabular}

melting. Second, The DTA spectrum of their AZ91 $+0.5 \mathrm{Sb}$ alloy at temperature higher than the $\alpha-\mathrm{Mg}$ phase melting temperature is different with their other two 


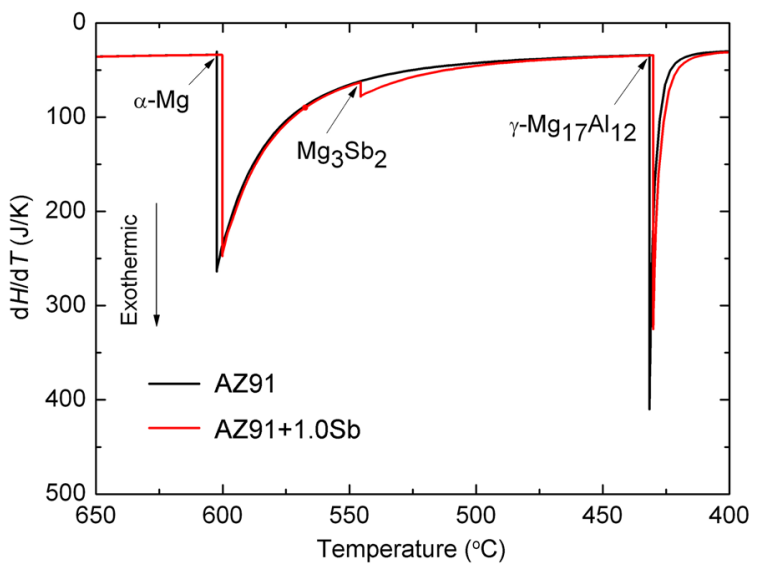

Fig. 6 Comparison of the derivatives of total enthalpy $(\mathrm{d} H / \mathrm{d} T)$ versus Temperature of AZ91 and AZ91 + 1.0Sb alloy under Scheil solidification simulation condition, a small peak referring to the formation of $\mathrm{Mg}_{3} \mathrm{Sb}_{2}$ phase can be easily seen at $546{ }^{\circ} \mathrm{C}$ on the curve of $\mathrm{AZ} 91+1.0 \mathrm{Sb}$ alloy

Table 3 Predicted precipitation temperature of the three main phases under Scheil simulation

\begin{tabular}{llll}
\hline Alloys & $T_{\alpha-\mathrm{Mg}}\left({ }^{\circ} \mathrm{C}\right)$ & $T_{\mathrm{Mg} 3 \mathrm{Sb} 2}\left({ }^{\circ} \mathrm{C}\right)$ & $T_{\gamma \text {-Mg17A112 }}\left({ }^{\circ} \mathrm{C}\right)$ \\
\hline $\mathrm{AZ91}$ & 603 & - & 432 \\
$\mathrm{AZ91}+0.1 \mathrm{Sb}$ & 602 & 477 & 432 \\
$\mathrm{AZ91}+0.5 \mathrm{Sb}$ & 598 & 528 & 431 \\
$\mathrm{AZ91}+1.0 \mathrm{Sb}$ & 600 & 546 & 430 \\
\hline
\end{tabular}

alloys (AZ91 and AZ91 + Pb). DTA spectrums of AZ91 and $\mathrm{AZ91}+\mathrm{Pb}$ alloys are kept linear at the temperature higher than the $\alpha-\mathrm{Mg}$ phase melting temperature, while heat flow of AZ91 $+0.5 \mathrm{Sb}$ alloy increases rapidly after that temperature. The heat flow in the liquid state should be linear with ratio to the heat capacity of the liquid phase. The abnormal trend shown in the DTA spectrum of $\mathrm{AZ91}+0.5 \mathrm{Sb}$ alloy implies some unexpected reactions happened. According to our experiences on DTA experiments, their DTA measurement were carried out under Ar atmosphere, with open alumina crucible, if the experiment condition was not well controlled, the $\mathrm{Mg}$ melt could evaporate readily, and the strong thermal event after the melting of $\alpha-\mathrm{Mg}$ phase should be refer to the evaporation of the $\mathrm{Mg}$ melt, rather than the $\mathrm{Mg}_{3} \mathrm{Sb}_{2}$ phase. Third, a tiny thermal signal at about $550{ }^{\circ} \mathrm{C}$ in the DTA spectrum of $\mathrm{AZ91}+0.5 \mathrm{Sb}$ alloy, which should be the $\mathrm{Mg}_{3} \mathrm{Sb}_{2}$ phase signal and essentially in agreement with the present thermodynamic calculations, was ignored by Balasubramani et al. [10]. On the other hand, Balasubramani et al. [10] also determined the liquidus temperature of the alloys within temperature range from 589.3 to $596.65{ }^{\circ} \mathrm{C}$, however the temperature of the first peaks on the heating curve,

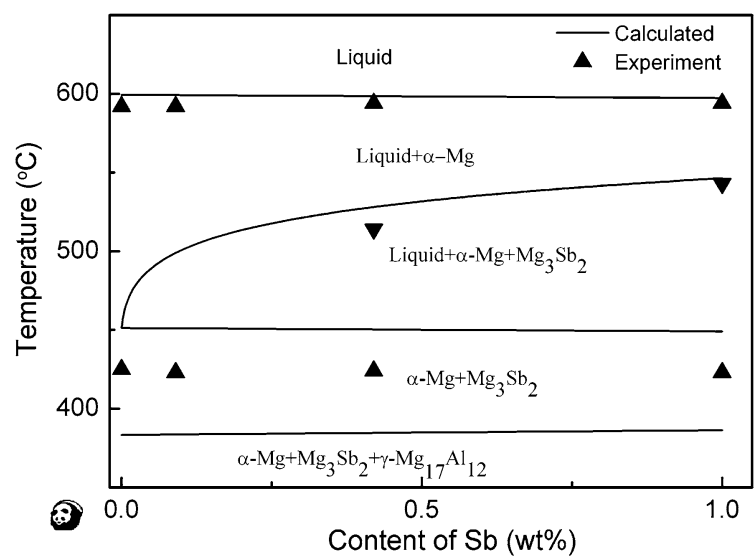

Fig. 7 Calculated equilibrium vertical section of $\mathrm{Mg}-9 \mathrm{Al}-1.0 \mathrm{Zn}-$ $x$ Sb system

which refer to the liquidus temperature of the alloys as explained by Beottinger et al. [33], are clearly slightly higher than $600{ }^{\circ} \mathrm{C}$ in their DTA spectra. In addition, the $\mathrm{Mg}_{3} \mathrm{Sb}_{2}$ particles or needles are often distributed along grain boundaries, interdendritic region of $\alpha-\mathrm{Mg}$ phase, or entrapped by $\gamma-\mathrm{Mg}_{17} \mathrm{Al}_{12}$ phase as observed in this work and previous publications [10-12, 16, 17]. No researcher has observed $\mathrm{Mg}_{3} \mathrm{Sb}_{2}$ phase in the central of $\alpha-\mathrm{Mg}$ phase as a nucleation site. Therefore, the assumption on $\mathrm{Mg}_{3} \mathrm{Sb}_{2}$ phase in $\mathrm{AZ} 91+\mathrm{Sb}$ alloys is against the experimental proofs and unacceptable.

\subsection{Dendrite Coherency Point (DCP) of AZ91 $+\mathrm{xSb}$ Alloys}

The formation of solidification microstructure, such as dendrite size and morphology, is suggested to be strongly dependent on dendrite coherency of the alloy [34]. Therefore, the knowledge of DCP is essential to understand microstructure formation during solidification [34, 35]. Basically, a higher $f_{\mathrm{s}}^{\mathrm{DCP}}$ corresponds to a finer grain size, thus the rise of $f_{\mathrm{s}}^{\mathrm{DCP}}$ can be regarded as an indicator for grain refinement. As mentioned previously, the dendrite coherency temperature of the alloys $\left(T_{\mathrm{DCP}}\right)$ was determined by thermal analysis results. And the relationship between solid fraction and temperature is also calculated form thermal analysis results showing in Fig. 5. Thus, the $f_{\mathrm{s}}^{\mathrm{DCP}}$ can be determined.

Figure 7 shows the value of $f_{\mathrm{s}}^{\mathrm{DCP}}$ for $\mathrm{AZ91}+x \mathrm{Sb}$ alloys. As seen in Fig. 7, the value of $f_{\mathrm{s}}^{\mathrm{DCP}}$ decreases slightly from 40 to $35 \mathrm{vol} \%$ as $\mathrm{Sb}$ content increases from 0 to $1.0 \mathrm{wt} \%$, which means that dendrites start interacting at a little earlier stage of solidification with increasing $\mathrm{Sb}$ content. Thus, a slight growth of the AGS occurs with increasing $\mathrm{Sb}$ content is indicated, which is in consistent with the EBSD observations shown previously in the present research (Fig. 8). 


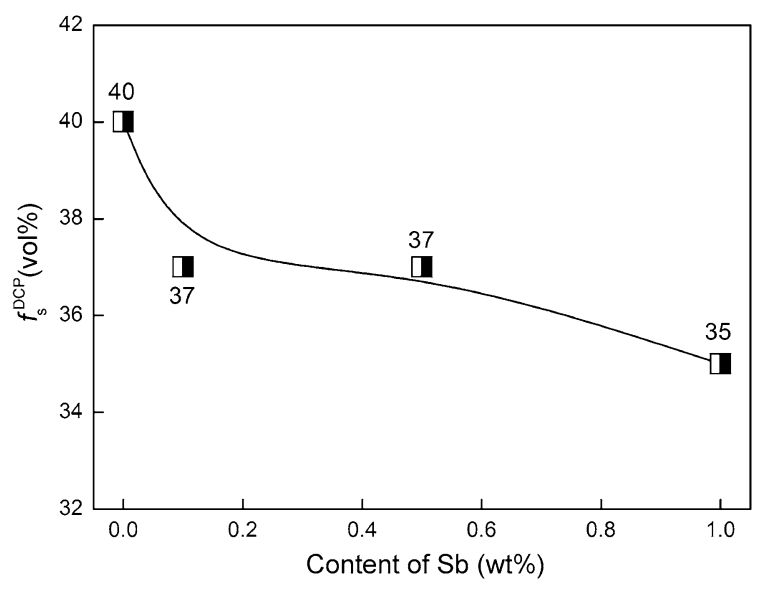

Fig. 8 Effect of $\mathrm{Sb}$ concentration on solid fraction at dendrite coherency $\left(f_{\mathrm{s}}^{\mathrm{DCP}}\right)$ of AZ91 $+x \mathrm{Sb}$ alloys

\section{Conclusions}

The effects of $\mathrm{Sb}$ addition on solidification pathways and grain size of $\mathrm{AZ91}+x \mathrm{Sb}(x=0,0.1,0.5,1$, in wt $\%)$ alloys were reconsidered mainly based on EBSD observation, thermal analysis, and thermodynamic calculations. It was found that the non-equilibrium solidification microstructure of $\mathrm{AZ91}+x \mathrm{Sb}(x=0.1,0.5,1)$ is composed of $\alpha$-Mg matrix, $\beta-\mathrm{Mg}_{17} \mathrm{Al}_{12}$ phase, and intermetallic compound $\mathrm{Mg}_{3} \mathrm{Sb}_{2}$. When $\mathrm{Sb}$ was added into AZ91 alloy, no grain refinement effect was detected from EBSD images of the solidification microstructure. And it was found that the $\mathrm{Mg}_{3} \mathrm{Sb}_{2}$ phase forms after $\alpha-\mathrm{Mg}$ nucleation, which made it impossible for $\mathrm{Mg}_{3} \mathrm{Sb}_{2}$ particles to act as heterogeneous nucleus for $\alpha-\mathrm{Mg}$ dendrite. Besides, the decreasing of $f_{\mathrm{s}}^{\mathrm{DCP}}$ value with increasing $\mathrm{Sb}$ content further confirms the fact that $\mathrm{Sb}$ does not refine the grain size of AZ91 alloy.

Acknowledgments This work was financially supported by the National Basic Research Program of China (No. 2013CB632202) and the National Natural Science Foundation of China (Nos. 51105350 and 51301173) is acknowledged. Dr. J.L. Li is also acknowledged for his kind English revision on this manuscript.

\section{References}

[1] A.A. Luo, Int. Mater. Rev. 49, 13 (2004)

[2] A.A. Luo, J. Magnes. Alloys 1, 2 (2013)

[3] C. Zhang, W. Cao, S.L. Chen, J. Zhu, F. Zhang, A.A. Luo, R. Schmid-Fetzer, JOM 66, 389 (2014)

[4] J. Xu, G. H. Wu, W.C. Liu, Y. Zhang, W. J. Ding, J. Magnesium Alloys 1, (2013)
[5] J. Liu, S. Lu, X. Dong, X. Xiao, G. Li, Met. Sci. Heat Treat. 55, 427 (2013)

[6] A. Zafari, H.M. Ghasemi, R. Mahmudi, Mater. Des. 54, 544 (2014)

[7] Y.A. Chen, H. Liu, R. Ye, G. Liu, Mater. Sci. Eng. A 587, 262 (2013)

[8] G. Mao, Q. Liu, Foundry 59, 614 (2010)

[9] H.L. Zhao, S.K. Guan, F.Y. Zheng, J. Mater. Res. 22, 2423 (2007)

[10] N. Balasubramani, A. Srinivasan, U.T.S. Pillai, B.C. Pai, Mater. Sci. Eng. A 457, 275 (2007)

[11] Z. Yang, J. Li, J. Chang, H. Wang, X. Zhu, K. Zhang, S. Yu, Y. Cao, Hot Work. Technol. 5, 18 (2004)

[12] G.Y. Yuan, Y.S. Sun, W.J. Ding, Scr. Mater. 43, 1009 (2000)

[13] K.S. Sun, W.M. Zhang, X.G. Min, Acta Metall. Sin. (Engl. Lett.) 14, 330 (2001)

[14] Y.S. Wang, J.Z. Yu, Q.W. Wang, W.J. Ding, Acta Metall. Sin. (Engl. Lett.) 16, 8 (2003)

[15] Z. Yang, J.P. Li, J.X. Zhang, G.W. Lorimer, J. Robson, Acta Metall. Sin. (Engl. Lett.) 21, 313 (2008)

[16] A. Srinivasan, J. Swaminathan, M.K. Gunjan, U.T.S. Pillai, B.C. Pai, Mater. Sci. Eng. A 527, 1395 (2010)

[17] N. Balasubramani, A. Srinivasan, U.T.S. Pillai, K. Raghukandan, B.C. Pai, J. Alloys Compd. 455, 168 (2008)

[18] G. Nayyeri, R. Mahmudi, Mater. Sci. Eng. A 527, 669 (2010)

[19] Q.D. Wang, W.H. Chen, W.J. Ding, Y.P. Zhu, M. Mabuchi, Metall. Mater. Trans. A 32, 787 (2001)

[20] B.S. Wang, R.L. Xin, G.J. Huang, X.P. Chen, Q. Liu, J. Chin. Electron Microsc. Soc. 28, 20 (2009)

[21] N. Gao, S.C. Wang, H.S. Ubhi, M.J. Starink, J. Mater. Sci. 40, 4971 (2005)

[22] H. Jafari, M.H. Idris, A. Ourdjini, S. Farahany, Mater. Des. 50, 181 (2013)

[23] S. Farahany, H.R. Bakhsheshi-Rad, M.H. Idris, M.R.A. Kadir, A.F. Lotfabadi, A. Ourdjini, Thermochim. Acta 527, 180 (2012)

[24] S.M. Liang, R.S. Chen, J.J. Blandin, M. Suery, E.H. Han, Mater. Sci. Eng. A 480, 365 (2008)

[25] A.K. Dahle, P.A. Tondel, C.J. Paradies, L. Arnberg, Metall. Mater. Trans. A 27, 2305 (1996)

[26] M. Malekan, S.G. Shabestari, Metall. Mater. Trans. A 40, 3196 (2009)

[27] T. Balakumar, M. Medraj, Calphad 29, 24 (2005)

[28] M. Paliwal, I.H. Jung, Calphad 34, 51 (2010)

[29] P. Liang, T. Tarfa, J.A. Robinson, S. Wagner, P. Ochin, M.G. Harmelin, H.J. Seifert, H.L. Lukas, F. Aldinger, Thermochim. Acta 314, 87 (1998)

[30] S. Thompson, S.L. Cockcroft, M.A. Wells, Mater. Sci. Technol. 20, 194 (2004)

[31] M. Ohno, D. Mirković, R. Schmid-Fetzer, Acta Mater. 54, 3883 (2006)

[32] W. Cao, S.L. Chen, F. Zhang, K. Wu, Y. Yang, Y.A. Chang, R. Schmid-Fetzer, W.A. Oates, Calphad 33, 328 (2009)

[33] W.J. Boettinger, U.R. Kattner, K. W. Moon, J.H. Perepezko, DTA and heat-flux DSC measurements of alloy melting and freezing, (NIST, U.S. Government Printing Office, 2006), p 22

[34] L. Arnberg, G. Chai, L. Backerud, Mater. Sci. Eng. A 173, 101 (1993)

[35] D. Emadi, L.V. Whiting, S. Nafisi, R. Ghomashchi, J. Thermal Anal. Calorim. 81, 235 (2005) 